\title{
Early outcomes of deliberate nonoperative management for blunt thoracic aortic injury in trauma
}

\author{
Anthony D. Caffarelli, MD, ${ }^{\mathrm{a}}$ Hari R. Mallidi, MD, ${ }^{\mathrm{a}}$ Paul M. Maggio, MD, MBA, ${ }^{\mathrm{b}}$ David A. Spain, MD, ${ }^{\mathrm{b}}$ \\ D. Craig Miller, MD, ${ }^{a}$ and R. Scott Mitchell, MD $^{a}$
}

Objective: Traumatic blunt aortic injury has traditionally been viewed as a surgical emergency, whereas nonoperative therapy has been reserved for nonsurgical candidates. This study reviews our experience with deliberate, nonoperative management for blunt thoracic aortic injury.

\begin{abstract}
Methods: A retrospective chart review with selective longitudinal follow-up was conducted for patients with blunt aortic injury. Surveillance imaging with computed tomography angiography was performed. Nonoperative patients were then reviewed and analyzed for survival, evolution of aortic injury, and treatment failures.

Results: During the study period, 53 patients with an average age of 45 years (range, 18-80 years) were identified, with $28 \%$ presenting to the Stanford University School of Medicine emergency department and $72 \%$ transferred from outside hospitals. Of the 53 patients, 29 underwent planned, nonoperative management. Of the 29 nonoperative patients, in-hospital survival was $93 \%$ with no aortic deaths in the remaining patients. Survival was $97 \%$ at a median of 1.8 years (range, 0.9-7.2 years). One patient failed nonoperative management and underwent open repair. Serial imaging was performed in all patients (average $=107$ days; median, 31 days), with 21 patients having stable aortic injuries without progression and 5 patients having resolved aortic injuries.
\end{abstract}

Conclusions: This experience suggests that deliberate, nonoperative management of carefully selected patients with traumatic blunt aortic injury may be a reasonable alternative in the polytrauma patient; however, serial imaging and long-term follow-up are necessary. (J Thorac Cardiovasc Surg 2010;140:598-605)

Earn CME credits at

http://cme.ctsnetjournals.org

Since the classic autopsy series by Parmley and colleagues ${ }^{1}$ in 1958, prompt diagnosis and early operative repair have been the standard of care for the management of blunt aortic injury (BAI). Over the last decade with the advent of improved prehospital care and diagnostic imaging, more patients are arriving alive with a spectrum of recognized thoracic aortic injuries. In turn, the management of this injury has evolved to include partial bypass techniques for open repairs, thoracic endovascular aortic repair (TEVAR) options, delayed surgical repair, and nonoperative management in select cases.

Nonoperative management has traditionally been reserved for those patients who have contraindications to open repair,

\footnotetext{
From the Departments of Cardiothoracic Surgery and Surgery, ${ }^{\text {a }}$ and Section of Trauma/Critical Care Surgery, ${ }^{\mathrm{b}}$ Stanford University School of Medicine, Stanford, Calif.

Disclosures: None.

Received for publication July 9, 2009; revisions received Dec 31, 2009; accepted for publication Feb 1, 2010; available ahead of print June 25, 2010.

Address for reprints: Anthony D. Caffarelli, MD, Stanford University, Department of Cardiothoracic Surgery, 300 Pasteur Drive, Falk Building 2nd Floor, Stanford, CA 94305-5407 (E-mail: acaffare@stanford.edu).

$0022-5223 / \$ 36.00$

Copyright (c) 2010 by The American Association for Thoracic Surgery doi:10.1016/j.jtcvs.2010.02.056
}

primarily to temporize until definitive surgical or TEVAR repair can be undertaken. Little is known about the outcomes of nonoperative management except through subgroup analysis of nonsurgical candidates. ${ }^{2-4}$ There are limited studies that address deliberate nonoperative management strategies in surgical candidates with minimal aortic injuries (MAIs). ${ }^{5,6}$ The information that exists concerning deliberate nonoperative management of BAI is limited by small patient numbers with incomplete follow-up. Therefore, the natural history of the injured aorta managed nonoperatively, especially in more severe aortic injuries, is not well defined.

At Stanford University Medical Center, our management of BAI has evolved. Initially, urgent open repair was the standard; then over the years, delayed repair prevailed. Throughout the mid 1990s and early 2000s, we spearheaded the early TEVAR approach, ${ }^{7,8}$ but soon learned that this approach for BAI was hampered by unfavorable device characteristics and arterial access limitations. In addition, the long-term durability of these stent-grafts is unknown. Our reluctance to use TEVAR required us to reconsider the pathophysiology of BAI and treatment options. After assimilating our experience with the treatment of uncomplicated type B dissections, a deliberate strategy of nonoperative management of patients with BAI was more widely implemented. The principles of this strategy include aggressive negative inotropic therapy, routine serial imaging, and close clinical observation. The early results with this approach have been encouraging, and there has been a gradual 

Abbreviations and Acronym
BAI = blunt aortic injury
CT = computed tomography
MAI $=$ minimal aortic injury
SAI = significant aortic injury
SSDI = Social Security Death Index
TEVAR $=$ thoracic endovascular aortic repair

shift toward more deliberate nonoperative management for BAI in otherwise suitable surgical candidates. This report reviews our results of deliberate nonoperative management in BAI and provides insight into the fate of the injured aorta longitudinally after nonoperative treatment.

\section{MATERIALS AND METHODS}

Approval for this study was obtained from the institutional review board at Stanford University. All patients who were admitted or transferred with a diagnosis of BAI at a level I trauma center (Stanford University Medical Center) over the study period from January 2001 to May 2008 were identified from the trauma registry and transfer center database. A retrospective review of the hospital and outpatient clinic medical records was performed with longitudinal follow-up. Patients not surviving disposition from the emergency department or patients with injuries limited to a major branch of the aorta, such as the innominate, carotid, or subclavian arteries, were excluded from the review. Both the Cardiothoracic Surgery and Trauma services evaluated all patients, and the aortic treatment strategy was determined by the Cardiothoracic Surgery service.

Nonoperative therapy included admission to the intensive care unit with invasive cardiovascular monitoring. Treatment of stable patients was initiated with beta-blockade and afterload reduction as an adjunct if needed to maintain a systolic blood pressure between 100 and $120 \mathrm{~mm} \mathrm{Hg}$ and allowing for adequate end-organ perfusion. Serial helical computed tomography (CT) angiography was performed at 24 hours and then every 48 to 72 hours until the aortic injury was unchanged for 7 days. Absence of imaging characteristics of aortic instability (ie, pseudoaneurysm progression) prompted continued nonoperative management. At discharge, patients were recommended to have initial follow-up imaging at 1 month after injury and selectively thereafter.

Data regarding patient demographics, associated injuries, Injury Severity Scores, Abbreviated Injury Scores, therapies, complications, and outcomes were gathered from the trauma registry and medical record review. Nonoperative patients were also reviewed and analyzed for (1) in-hospital and interval survival as determined through direct patient contact and crosschecking the Social Security Death Index (SSDI), (2) evolution of aortic injury through surveillance imaging, and (3) failure of nonoperative management as determined by measures of aortic instability (ie, progression of pseudoaneurysm size, dissection length, or expanding intraluminal or mural hematoma).

CT scans were reviewed, and injuries were categorized by location and radiographic grading. Injuries were defined anatomically as aortic arch, isthmus, or descending thoracic aorta. Radiographic grades were defined as intraluminal thrombus/intimal injury, mural injury, pseudoaneurysm less than $1 / 2$ aortic circumference, and pseudoaneurysm more than $1 / 2$ aortic circumference (Figure 1).

This is a descriptive, retrospective study that outlines our experience with deliberate, nonoperative therapy. Continuous variables were reported as mean \pm standard deviation. Categoric values were presented as percentages, and these were compared using the Pearson's chi-square test. SPSS version 11.5 (SPSS Inc, Chicago, Ill) was used to execute statistical tests. The authors had full access to and take full responsibility for the integrity of the data. All authors have read and agreed to the manuscript as written.

\section{RESULTS}

During the study period, 53 patients with BAI were identified among 8512 trauma admissions and transfers for an overall incidence of $0.62 \%$. Of the 53 patients, 38 were male and 15 were female. The average age was 45 years (range, 18-80 years). Twenty-eight percent of patients presented to the Stanford University School of Medicine emergency department, whereas $72 \%$ were transferred from other hospitals.

During the study period, 24 patients underwent operative management (9 open and 15 stent-graft repairs), and 29 patients underwent nonoperative management. From 2001 to 2004, 21 patients underwent operative repair and 4 patients underwent nonoperative management. From 2005 to 2008, 3 patients had operative repair and 25 patients had nonoperative management (Figure 2). Comparison of the 2 cohorts reveals no statistical difference in their demographics or in-hospital survival. The nonoperative group tended to have a lower Injury Severity Score, whereas the operative group tended to have more neurologic Abbreviated Injury Scores of 3 or more, but neither was statistically significant (Table 1).

Of the 29 nonoperative patients, the average length of stay was 18 days and in-hospital survival was $93 \%$ (27 patients) with no aortic ruptures. The 2 in-hospital deaths were autopsy proven, nonaortic deaths. One patient was an 18-year-old man involved in a high-speed motor vehicle collision who arrived in extremis. He first underwent emergency damage control laparotomy and external fixation of a grade III pelvic fracture, followed by pelvic arterial embolization. Arch angiogram revealed a nonextravasating aortic injury at the isthmus. Despite massive transfusion protocol and rewarming, the patient arrested secondary to coagulopathy within 8 hours of presentation to the emergency department. The second BAI death was an 80-year-old woman with coronary artery disease and prehospital do not resuscitate/do not intubate orders. She was a restrained passenger in a motor vehicle collision who was transferred for potential TEVAR after the diagnosis of BAI was made. She presented 3 days after injury and was in acute renal failure secondary to rhabdomyolysis. Nonoperative management was elected, and the patient died of hyperkalemic cardiac arrest on post-trauma day 5 .

Of the 27 survivors with nonoperative management, a breadth of aortic injury morphology was identified, ranging from subtle intraluminal filling defects to complex pseudoaneurysms (Table 2). Aortic injury location was predominately found at the isthmus, the usual location, but a minority $(26 \%)$ was seen in the descending thoracic aorta. Serial imaging was performed in all patients (average of 107 days; 


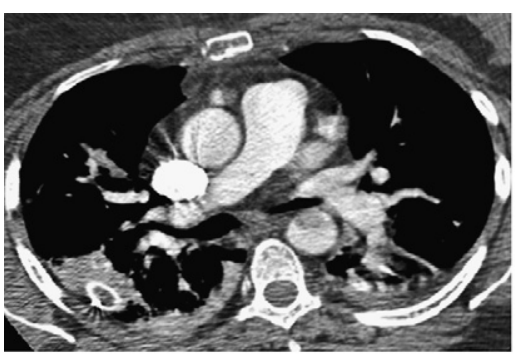

Intraluminal Filling Defect

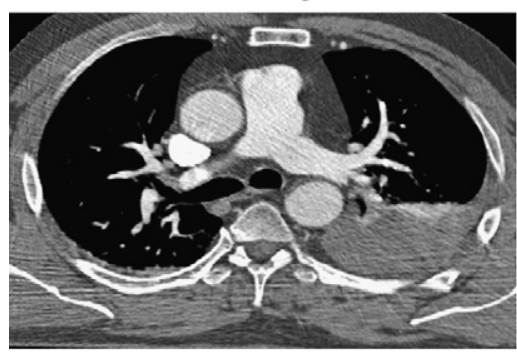

Mural Injury

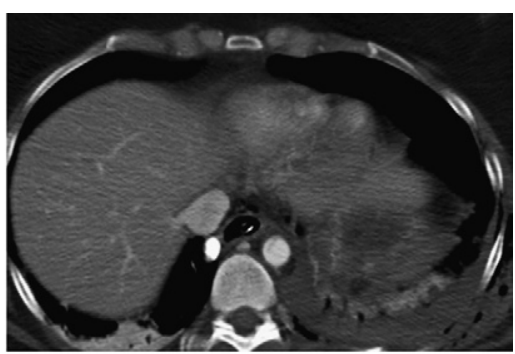

Intimal Injury

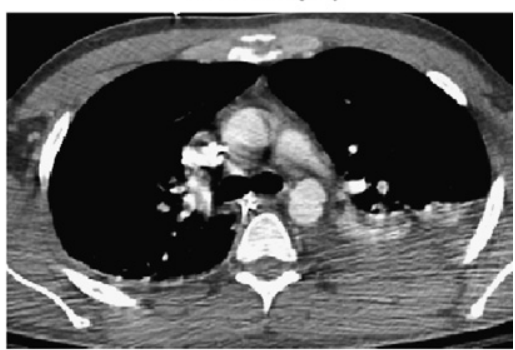

Pseudoaneurysm $<1 / 2$ aortic circumference

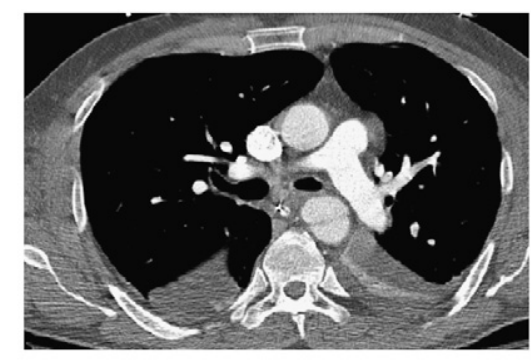

Pseudoaneurysm $>1 / 2$ aortic circumference

FIGURE 1. Computed tomography grading.

median, 31 days) (Table 3), with 50\% having longitudinal imaging studies more than 30 days after injury and $25 \%$ having imaging more than 100 days after injury. Of the 27 patients, 21 had stable aortic injuries without progression on follow-up imaging; 5 patients had complete resolution of their aortic injuries (4 with intraluminal thrombus-intimal injury and 1 with mural injury). One patient did fail nonoperative management because of pseudoaneurysm instability with progression from $1.7 \times 2.9 \mathrm{~cm}$ to $2.5 \times 3.8 \mathrm{~cm}$. She underwent open operative repair without incident. Of note, 2 patients with pseudoaneurysms underwent stent-graft placement after discharge from Stanford for unclear reasons at outside institutions, 1 of which had stent-graft collapse twice requiring 3 additional procedures.

Interval follow-up of nonoperative patients revealed 17 patients $(67 \%)$ were confirmed alive by patient interviews, 1 patient with a stable pseudoaneurysm died of a nonaortic cause (acute liver failure), and 8 patients (33\%) were not listed in the SSDI as of April 1, 2009. Assuming the worst case scenario that all 8 patients died of aortic rupture and are censored as such, then the actual survival is $67 \%$. All 8 patients, however, did have social security num- bers, and the SSDI did not reveal any deaths; therefore, a survival of $97 \%$ at a median of 1.8 years (range, $0.9-7.2$ years) can probably be imputed with some certainty.

\section{DISCUSSION}

Blunt traumatic thoracic aortic injury has traditionally been managed as a surgical emergency. Multiple studies, however, have reported the safety of delayed repair (operative or TEVAR) in polytrauma patients. ${ }^{9}$ In high-risk patients with multiple major associated injuries, advanced age, or other severe morbid conditions, a deliberate nonoperative approach may be a reasonable option. Over the years at Stanford University School of Medicine, nonoperative management has evolved from a bridging strategy toward definitive surgical or TEVAR repair to one of expectant observation in many patients.

The evolution of our management of patients with BAI can largely be attributed to the increased recognition of a variety of aortic injuries. Initially, the diagnosis of BAI was made by chest x-rays and aortography, which would identify only the more complex aortic injuries. Contrast-enhanced CT, with multidetector-row technology and multiplanar 


$\begin{array}{lcccccccc}\text { Year } & 2001 & 2002 & 2003 & 2004 & \mathbf{2 0 0 5} & \mathbf{2 0 0 6} & \mathbf{2 0 0 7} & \mathbf{2 0 0 8} \\ \text { Non-OP } & 1 & 2 & 1 & 0 & 5 & 5 & 14 & 1 \\ \text { Operative } & 4 & 2 & 6 & 9 & 1 & 2 & 0 & 0 \\ & & & & & & & & \\ \text { stent } & 1 & 1 & 6 & 6 & 0 & 1 & - & - \\ \text { open } & 3 & 1 & 0 & 3 & 1 & 1 & -\end{array}$

\section{Operative vs Non-Operative Management by Years}

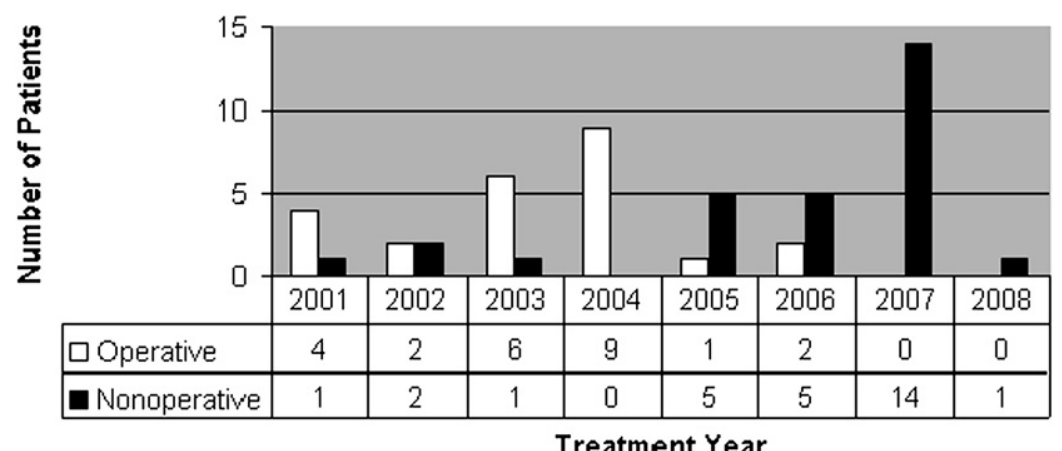

FIGURE 2. Operative versus nonoperative management by year.

reformulations, is the current diagnostic modality of choice to screen for traumatic aortic injury. ${ }^{10}$ These high-quality images and transesophageal echocardiography allow more refined assessment of the aortic wall and recognition of a spectrum of aortic injuries that likely would not have been identified by catheter-based angiography. ${ }^{11,12}$ Direct signs of aortic injury include active extravasation of contrast,

TABLE 1. Demographics of all patients with blunt thoracic aortic injuries stratified by nonoperative and operative management

\begin{tabular}{lccc}
\hline \multicolumn{1}{c}{ Variable } & $\begin{array}{c}\text { Nonoperative } \\
\mathbf{n = 2 9}\end{array}$ & $\begin{array}{c}\text { Operative } \\
\mathbf{n = 2 4}\end{array}$ & $\boldsymbol{P}$ \\
\hline Age (y: mean \pm SD) & $45 \pm 15$ & $46 \pm 20$ & \\
Gender & & & \\
$\quad$ Male & 20 & 18 & \\
$\quad$ Female & 9 & 6 & \\
Presentation & & & \\
$\quad$ Stanford & $8(30 \%)$ & $7(29 \%)$ & \\
$\quad$ Outside hospital & $21(70 \%)$ & $17(71 \%)$ & \\
Associated injuries & & & \\
$\quad$ Major head/neck injury (AIS $\geq 3)$ & $23 \%$ & $50 \%$ & .36 \\
$\quad$ Major abdominal injury (AIS $\geq 3)$ & $20 \%$ & $21 \%$ & .35 \\
$\quad$ Major pelvic injury (AIS $\geq 3)$ & $43 \%$ & $29 \%$ & .31 \\
$\quad$ Combined major head & $3 \%$ & $13 \%$ & \\
$\quad$ and abdominal & & & \\
$\quad$ Injury Severity Score & $32.2 \pm 10.3$ & $36.4 \pm 10.2$ & .14 \\
In-hospital survival & $93 \%$ & $92 \%$ & \\
Length of stay (d: average \pm SD) & $18 \pm 11$ & $26 \pm 20$ & \\
\hline PIS, Abbrian
\end{tabular}

AIS, Abbreviated Injury Score; $S D$, standard deviation. pseudoaneurysm formation, intimal flaps, luminal filling defects, and intramural hematoma. Indirect signs of aortic injury include periaortic hematoma, mediastinal hematoma, and hemothorax. ${ }^{13}$ Therefore, a spectrum of aortic injury patterns can result from BAI. The term minimal aortic injury (MAI) has been used to describe a lesion of the aorta associated with BAI that is believed to carry a relatively low risk of rupture, ${ }^{14}$ with an incidence of approximately $10 \%$ in the current era. ${ }^{6}$ The term "significant aortic injury" (SAI) has been used to describe all other injury patterns and typically mandates surgical or TEVAR repair if the risk-benefit ratio is favorable. If nonoperative management is to be pursued, it is imperative that MAI be differentiated from SAI. ${ }^{6} \mathrm{~A}$ review of the current literature, in which nonoperative management of BAI was reported ( $\geq 5$ patients with $\mathrm{BAI})$ along with the reason for a nonoperative management strategy and outcomes, is listed in Table 4. At Stanford, we recently applied

TABLE 2. Aortic injury morphology and location in the nonoperative survivors

\begin{tabular}{lccc}
\hline & \multicolumn{3}{c}{ Injury location } \\
\cline { 2 - 4 } \multicolumn{1}{c}{ Injury type } & Arch & Isthmus & Descending \\
\hline Intraluminal thrombus/intimal injury & - & 2 & 4 \\
Mural hematoma & - & 1 & 1 \\
$\begin{array}{l}\text { Pseudoaneurysm }<\frac{1}{2} \text { aortic } \\
\quad \text { circumference }\end{array}$ & 1 & 15 & 2 \\
$\begin{array}{l}\text { Pseudoaneurysm }>1 / 2 \text { aortic } \\
\quad \text { circumference }\end{array}$ & - & 1 & - \\
\hline
\end{tabular}


TABLE 3. Post-injury follow-up imaging days for nonoperative survivors stratified by aortic injury morphology

\begin{tabular}{lccc}
\hline & $\begin{array}{c}\text { All nonoperative } \\
(\mathbf{n}=\mathbf{2 7})\end{array}$ & $\begin{array}{c}\text { Nonoperative } \\
\text { minor injury } \\
(\mathbf{n}=\mathbf{8})\end{array}$ & $\begin{array}{c}\text { Nonoperative } \\
\text { pseudoaneurysms } \\
(\mathbf{n}=\mathbf{1 9})\end{array}$ \\
\hline Median (d) & 31 & 31 & 31 \\
Average (d) & 105 & 81 & 114 \\
Range (d) & $1-641$ & $3-298$ & $1-641$ \\
\hline
\end{tabular}

nonoperative management to those patients with MAI and select patients with SAI, but have reserved operative treatment for individuals with more complex pseudoaneurysms and complete aortic transections.

Experience with other aortic diseases has helped shape our current approach. One cannot assume that the natural history of a traumatic aortic lesion will behave similarly in patients with different underlying pathologies. Patients who have aortic aneurysms from degenerative or connective tissue disorders are at elevated risk of acute rupture of the aorta because of the inherent underlying abnormality of the layers of the aortic wall. However, the same is not true for the majority of trauma patients who tend to be relatively young. Generally, the adventitia and connective tis- sue of patients with trauma is acutely injured but inherently normal; therefore, institution of strict medical management for more than just MAI may be safe. The recommendation for urgent surgery is based on the belief that BAI is an unstable lesion that will unexpectedly progress to aortic rupture with exsanguination. In the current era, the basis for these assumptions in the trauma patient with multiple injuries may be inaccurate. With the implementation of aggressive anti-impulse therapy and serial imaging, aortic ruptures were not experienced by others ${ }^{2,6,15}$ or in our current study.

The foundation of a nonoperative approach is the institution of an aggressive negative inotropic and antihypertensive regimen. This includes the initiation of $\beta$-blocker therapy and, when needed, supplementation with a vasodilator to reduce the aortic wall shear forces (aortic $\mathrm{dP} / \mathrm{dt}$ ). ${ }^{9}$ This concept was first described by Akins and colleagues ${ }^{4}$ from the Massachusetts General Hospital and concurrently initiated by Pate in Memphis in the 1970s with similar results. Our practice for those patients without neurologic injuries who can tolerate permissive hypotension is to target the systolic blood pressure to 100 to $120 \mathrm{~mm} \mathrm{Hg}$ with ongoing assessment of end-organ perfusion. One caveat is the ability of the patients to tolerate permissive hypotension and to

TABLE 4. Literature review of nonoperative patients with reported outcomes

\begin{tabular}{|c|c|c|c|c|c|}
\hline Study authors (year) & $\begin{array}{c}\text { Primary } \\
\text { nonoperative } \\
\text { focus (yes/no) } \\
\end{array}$ & $\begin{array}{c}\text { No. of nonoperative } \\
\text { patients }\end{array}$ & $\begin{array}{c}\text { Reason for } \\
\text { nonoperative } \\
\text { management } \\
\end{array}$ & $\begin{array}{c}\text { Anti-impulse } \\
\text { therapy (Yes/No) }\end{array}$ & Follow-up \\
\hline Akins and colleagues $(1980)^{4}$ & No & $5 / 44$ & Nonsurgical & Yes & All 5 patients discharged alive \\
\hline Fabian and colleagues $(1997)^{3}$ & No & $21 / 274$ & Nonsurgical & Yes (only $17 \%$ ) & $\begin{array}{l}11 / 21 \text { died of associated injuries, } \\
\text { no aortic ruptures }\end{array}$ \\
\hline Fabian and colleagues $(1998)^{15}$ & No & $19 / 71$ & $\begin{array}{l}13 \text { nonsurgical } \\
6 \mathrm{MAI}\end{array}$ & Yes & $\begin{array}{l}13 \text { nonsurgical } \\
9 \text { died } \\
4 \text { survived } \\
\text { - } 3 \text { stable injuries } \\
\quad(1 \text { MAI, } 2 \text { pseudoaneurysms }) \\
\text { - } 1 \text { resolved } \\
6 \text { MAI: } \\
5 \text { resolved } \\
1 \text { stable }\end{array}$ \\
\hline Malhotra and colleagues $(2001)^{6}$ & Yes & $\begin{array}{l}8 \text { SAI } \\
6 \text { MAI }\end{array}$ & $\begin{array}{l}8 \text { nonsurgical } \\
6 \text { MAI }\end{array}$ & Yes & $\begin{array}{l}2 / 8 \text { nonsurgical survived } \\
1 \text { resolved } \\
1 \text { stable } \\
6 \text { MAI } \\
2 \text { resolved } \\
1 \text { indeterminate } \\
2 \text { stable pseudoaneurysms } \\
1 \text { progressed } \rightarrow \text { repaired }\end{array}$ \\
\hline Holmes and colleagues $(2002)^{2}$ & Yes & $15 / 30$ & Nonsurgical & Yes & $\begin{array}{l}5 / 15 \text { died, no aortic rupture } \\
10 / 15 \text { survived } \\
5 \text { resolved } \\
5 \text { stable }\end{array}$ \\
\hline Kepros and colleagues (2002)* & Yes & 5 & MAI & Yes & All 5 resolved within $19 \mathrm{~d}$ \\
\hline
\end{tabular}

*Kepros J, Angood P, Jaffe CC, Rabinovici R. Aortic intimal injuries from blunt trauma: resolution profile in nonoperative management. J Trauma. 2002;52:475-8. MAI, Minimal aortic injury. 
comply with serial imaging to identify treatment failures. Our 1 patient with treatment failure may have progressed to rupture, but serial imaging identified an enlarging pseudoaneurysm that led to definitive open repair.

To date, nonoperative management has traditionally been reserved for nonsurgical candidates, but some have advocated nonoperative therapy for patients with MAI with relatively good results (Table 4). Our knowledge of whether this is prudent, however, is constrained by small patient numbers with limited and incomplete follow-up. Our study reports the application of nonoperative management to patients without contraindications to surgical therapy, as demonstrated by the lower Injury Severity Score (32.2 \pm 10.3 vs $36.4 \pm 10.2$ ). In addition, we have applied this strategy to include more than just MAI (intraluminal thrombus/intimal injury/mural injury), with the majority of our patients $(70 \%)$ having small to moderate pseudoaneurysms $(<3 \mathrm{~cm})$. Furthermore, the majority of these patients with SAI (21/27) had stable aortic injuries without progression on follow-up imaging, and 5 patients had complete resolution.

Because of the potentially disastrous consequences of not repairing an SAI and significant medicolegal implications, most centers continue to repair all traumatic aortic injuries, except in situations in which there are major contraindications to surgery. ${ }^{6}$ Some groups are now advocating TEVAR as the primary treatment of BAI ${ }^{14}$; however, TEVAR currently has attendant difficulties, namely, small-size commercial device availability that will conform to a tight radius of curvature of the aortic arch. In addition, current devices have undergone fatigue testing only out to 10 years, and these patients may easily survive 30 to 50 more years. In the American Association for the Surgery of Trauma multicenter study in 2008, the second largest prospective study of patients with BAI, $65 \%$ of all patients, $60 \%$ of patients with no major extrathoracic injuries, and $57 \%$ of patients aged 55 years or more and with no major extrathoracic trauma were managed with stent-grafts. ${ }^{16}$ Others have gone so far as to say that " although the natural history of residual pseudoaneurysms seems to follow those of nontraumatic atherosclerotic aneurysms, these lesions should not, especially in young patients, be considered completely benign, and the authors favor early intervention as soon as medically stable." 17 The Stanford philosophy is that these aortic injuries, especially pseudoaneurysms, are different than nontraumatic atherosclerotic aneurysms because in the majority of trauma patients, the underlying aortic pathology does not exist. Limited stentgraft device sizes, configurations, conformability, and lack of long-term device durability data have limited our enthusiasm for early endovascular intervention. We exercise caution in using TEVAR in BAI given the $20 \%$ incidence of serious, early graft-related complications seen in the American Association for the Surgery of Trauma multicenter study. ${ }^{16,18} \mathrm{We}$ do advocate TEVAR in nonoperative candidates with neurologic injuries that preclude the use of permissive hypotension or anticoagulation during open repair.

\section{Limitations}

Several factors limit the inferences that can be drawn from our observations. Follow-up was not available for 8 of our patients, a frequent problem with this trauma population, which further limits these observations. Even though the number of patients is more than previously reported, the cohort is still small and underpowered. In addition, we have a low event rate for treatment failures (only $1 / 27$ patients had progression of the aortic injury). Finally, this is a retrospective study that could suffer from uncontrolled bias.

\section{CONCLUSIONS}

The present study provides novel information regarding the nonoperative management of stable patients with BAI with a spectrum of aortic injuries, as well as longitudinal assessment of these injuries. First, this is the largest series to date of patients with BAI who were deliberately managed nonoperatively. Second, this is the first report to apply a nonoperative management strategy to otherwise operative candidates with more severe aortic injury patterns. Third, in this cohort of patients, nonoperative management was safe over the short-term with an in-hospital survival of $93 \%$ without any aortic ruptures. Finally, a spectrum of aortic injuries was identified, and longitudinal surveillance revealed that the majority of injuries remained stable $(78 \%)$, some completely resolved (18\%), and only 1 pseudoaneurysm $(4 \%)$ progressed, resulting in failure of nonoperative management. This experience suggests that deliberate nonoperative management of selected patients with traumatic aortic injuries may be a reasonable alternative in the polytrauma patient; however, serial imaging and long-term close follow-up of more patients clearly are necessary.

\section{References}

1. Parmley LF, Mattingly TW, Manion WC, Jahnke EJ Jr. Nonpenetrating traumatic injury of the aorta. Circulation. 1958;17:1086-101.

2. Holmes JHt, Bloch RD, Hall RA, Carter YM, Karmy-Jones RC. Natural history of traumatic rupture of the thoracic aorta managed nonoperatively: a longitudinal analysis. Ann Thorac Surg. 2002;73:1149-54.

3. Fabian TC, Richardson JD, Croce MA, Smith JS Jr, Rodman G Jr, Kearney PA, et al. Prospective study of blunt aortic injury: Multicenter Trial of the American Association for the Surgery of Trauma. J Trauma. 1997;42:374-83.

4. Akins CW, Buckley MJ, Daggett W, McIlduff JB, Austen WG. Acute traumatic disruption of the thoracic aorta: a ten-year experience. Ann Thorac Surg. 1981;31: 305-9.

5. Fisher RG, Oria RA, Mattox KL, Whigham CJ, Pickard LR. Conservative management of aortic lacerations due to blunt trauma. J Trauma. 1990;30:1562-6.

6. Malhotra AK, Fabian TC, Croce MA, Weiman DS, Gavant ML, Pate JW. Minimal aortic injury: a lesion associated with advancing diagnostic techniques. J Trauma. 2001;51:1042-8.

7. Kato N, Dake MD, Miller DC, Semba CP, Mitchell RS, Razavi MK, et al. Traumatic thoracic aortic aneurysm: treatment with endovascular stent-grafts. Radiology. 1997;205:657-62.

8. Demers P, Miller C, Scott Mitchell R, Kee ST, Lynn Chagonjian RN, Dake MD. Chronic traumatic aneurysms of the descending thoracic aorta: mid-term results of 
endovascular repair using first and second-generation stent-grafts. Eur J Cardiothorac Surg. 2004;25:394-400.

9. Brinkman WT, Szeto WY, Bavaria JE. Overview of great vessel trauma. Thorac Surg Clin. 2007; 17:95-108.

10. Melton SM, Kerby JD, McGiffin D, McGwin G, Smith JK, Oser RF, et al. The evolution of chest computed tomography for the definitive diagnosis of blunt aortic injury: a single-center experience. J Trauma. 2004;56:243-50.

11. Gavant ML. Helical CT grading of traumatic aortic injuries. Impact on clinical guidelines for medical and surgical management. Radiol Clin North Am. 1999; 37:553-74, vi.

12. Gavant ML, Flick P, Menke P, Gold RE. CT aortography of thoracic aortic rupture. AJR Am J Roentgenol. 1996;166:955-61.

13. Rivas LA, Munera F, Fishman JE. Multidetector-row computerized tomography of aortic injury. Semin Roentgenol. 2006;41:226-36.

14. Neschis DG, Scalea TM, Flinn WR, Griffith BP. Blunt aortic injury. N Engl J Med. 2008;359:1708-16.

15. Fabian TC, Davis KA, Gavant ML, Croce MA, Melton SM, Patton JH Jr, et al. Prospective study of blunt aortic injury: helical CT is diagnostic and antihypertensive therapy reduces rupture. Ann Surg. 1998;227:666-77.

16. Demetriades D, Velmahos GC, Scalea TM, Jurkovich GJ, Karmy-Jones R, Teixeira PG, et al. Operative repair or endovascular stent graft in blunt traumatic thoracic aortic injuries: results of an American Association for the Surgery of Trauma Multicenter Study. J Trauma. 2008;64:561-71.

17. Karmy-Jones R, Nicholls S, Gleason TG. The endovascular approach to acute aortic trauma. Thorac Surg Clin. 2007;17:109-28.

18. Lin PH, Huynh TT, Kougias P, Wall MJ Jr, Coselli JS, Mattox KL. Endovascular repair of traumatic thoracic aortic injuries: a critical appraisal. Asian Cardiovasc Thorac Ann. 2008;16:337-45.

\section{Discussion}

Dr Timothy Van Natta (Torrance, Calif). I can tell you as a traumatologist this is very important work. It is true that the cohort size is small, 27 patients, and the follow-up time with a median 31 days is relatively short, but to paraphrase Dr Miller from yesterday, follow-up is short but still very valuable.

This work is important for 3 reasons. It is important because it is informed, and what I mean by that is the Stanford group was at the forefront of really tackling all kinds of thoracic aortic pathology with endovascular means. Others then followed suit, but the Stanford group was among the first to then bring to all of our attention a lot of cautions, and I think that has implications with regard to what you just talked about.

It is important because it is timely. There has been a virtual stampede to use this endovascular technology for blunt aortic injuries and other aortic pathology, and I think it is timely now that so many groups are reporting this kind of work that we take a step back and look at it critically and heed the cautions that you raise.

Finally, it is provocative. Of your 27 patients, $15 \mathrm{had}$ a significant pseudoaneurysm. That is $56 \%$. I think we are kind of trained to look at that and worry that the patient is a heartbeat away from a full rupture and dying, yet you have shown, albeit in this small population, that this may be the way to go. If you look at the American Association for the Surgery of Trauma report from last year looking at how this is tackled across the country, $20 \%$ of the patients have a significant procedure-related complication. So we should pay attention to that.

I do have 3 questions for you. The first relates to imaging. You stated that the imaging is all important as you work through your algorithm and you rely on computed tomography angiography. We and others use that to screen the patients, but then we rely heavily on intravascular ultrasound (IVUS) to help characterize whether this is just the tip of the iceberg when we see an intimal injury or there is something more to it, and it helps with the seat- ing of the endovascular device. You didn't mention the use of that. Do you use IVUS at all? If not, why not?

Dr Caffarelli. We do not use IVUS for characterization of the initial injury pattern. Luckily, at Stanford our CT angio group is very good with the quality of the images and the reformatted data, so we have not used IVUS. We have used IVUS more with the patients with aortic dissection and occasionally with stent grafts. We do not use IVUS.

Dr Van Natta. My second question relates to the patient population. It is a trauma patient population, notoriously difficult with regard to follow-up. Do you think it is appropriate to nonoperatively manage a group of patients with a median follow-up of 31 days?

Dr Caffarelli. It really brings to the forefront 2 kinds of approaches, either a selective treatment approach, as our group is suggesting, or treat all at once phenomenon, which other groups are suggesting with the endovascular therapy. I think the follow-up problem exists in both situations. We have thought about the stent-graft technology and seen problems with it, especially in this patient population, so we have opted to treat a little more critically. In our small cohort of patients, only 1 patient progressed to operative therapy.

Dr Van Natta. Perhaps it is more important to follow the patients who have had the device placed than those who have not. You changed what you did because you saw some problems with the devices. As the devices evolved, you were limited because of the small aorta and its small radius of curvature, but because there are new devices, do you think your algorithm is going to change as they become available?

Dr Caffarelli. I think our group is going to have to face that, especially with some of the newer devices (eg, the CTAG from WL Gore and Associates, Inc, Newark, Del) coming on line with a smaller size and improved conformability. I think it is going to make our decision easier for the patients we do treat with TEVAR technology, such as the neurologically injured patients who do not tolerate permissive hypotension or some of the patients who have had more significant injuries, such as a larger more complex pseudoaneurysm. The big concern we have is durability of the device. We have only 10-year data as far as fatigue. In addition, what happens to the 20 -year-old trauma patient with a 20 -mm device who is going to live to 50 years? We just don't know the answer to that. I don't know if anyone else does.

Dr James Brown (Baltimore, Md). At R Adams Cowley Shock Trauma, we have developed a robust experience in traumatic aortic stent grafting spearheaded by Bart Griffith, our division chair. Congratulations on a thoughtful presentation.

With new therapeutic options, decisions become more difficult: what therapy for whom. I think the distillation of this could be extremely valuable, but if your report is read briefly, it may be extremely dangerous. Certainly what we have learned to fear are the torn aortas with extensive mediastinal hematoma, and that bears out in a couple of reports from Maryland. Second, the way we have gotten around the size discrepancy of available stent grafts in the past is to use the abdominal cuff extenders, which are small enough to match the aorta of young trauma patients. Would you comment on whether you have tried this technique? Finally, in the end analysis, assuming that the next technologic leap will be made and the right size stent graft is available to us for this repair technique, how will the algorithm change? In the end, surgeons with the expertise 
need to recommend to the world how this procedure should be performed.

Dr Caffarelli. We have previously used the extender technique, but not currently. We do have other device options becoming available. I think it may change things, but as of right now this is our primary treatment strategy for the patients without head trauma or more significant injury, but we do have to follow these patients. I think the shortcoming of the study is that we just don't have that long-term follow-up. It is in process, so we will just have to wait and see.

Dr Frank Baciewicz (Detroit, Mich). Does it make any difference in your initial decision whether to follow the patient or intervene-if the patient shows up in your emergency department or if he/she is transferred in from another institution? When patients are transferred to our center with this problem and they have been stable for a number of hours, we tend to watch them, whereas if they just come in with the recent injury, we tend to take them to the operating room more quickly.

Dr Caffarelli. The literature bears out that the biggest risk of aortic rupture is going to be in the first 48 to 96 hours; that is when the inflammatory process is the largest. Seventy percent of our patients came from the outside; therefore, the interval from injury to presentation at Stanford ranged from 1 day to $2 \frac{1}{2}$ weeks; so, yes, it has a bearing on our treatment strategy. The further patients are out from their injury, the more stable we believe they are going to be, especially if we are able to control their blood pressures. 